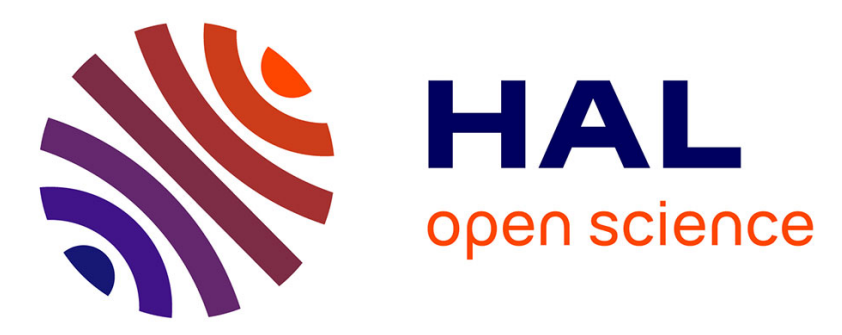

\title{
Towards an understanding approach of the insurance linked securities market
}

\author{
Mathieu Gatumel, Dominique Guegan
}

\section{To cite this version:}

Mathieu Gatumel, Dominique Guegan. Towards an understanding approach of the insurance linked securities market. 2008. halshs-00235354

\section{HAL Id: halshs-00235354 \\ https://shs.hal.science/halshs-00235354}

Submitted on 4 Feb 2008

HAL is a multi-disciplinary open access archive for the deposit and dissemination of scientific research documents, whether they are published or not. The documents may come from teaching and research institutions in France or abroad, or from public or private research centers.
L'archive ouverte pluridisciplinaire HAL, est destinée au dépôt et à la diffusion de documents scientifiques de niveau recherche, publiés ou non, émanant des établissements d'enseignement et de recherche français ou étrangers, des laboratoires publics ou privés. 


\section{Documents de Travail du Centre d'Economie de la Sorbonne}
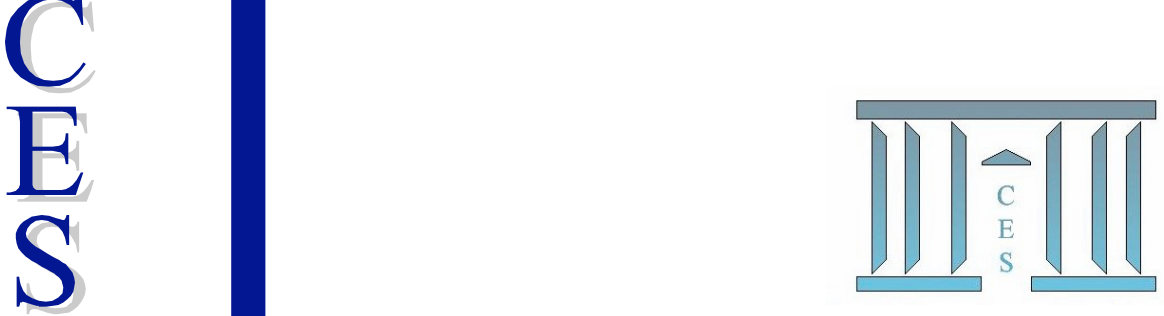

Towards an understanding approach of the insurance linked securities market

Mathieu GatumeL, Dominique GUEGAN

2008.06

CENTRE NATIONAL

DE LA RECHERCHE

SCIENTIFIQUE 


\title{
Towards an understanding approach of the Insurance Linked Securities Market
}

\author{
Mathieu Gatumel ${ }^{*}$ Dominique Guégan ${ }^{\dagger}$
}

January 22, 2008

\begin{abstract}
The paper aims to present the insurance linked securities market behaviour, that has changed a lot the past three years, both in terms of structure and in terms of ceded risks. After having introduced some stylized facts characterizing the insurance linked securities we capture their market price of risk, following the methodologies of Wang (2004), Lane (2000) and Fermat Capital Management (2005). A dynamical study of the insurance linked ecurities is also provided in order to understand the elements driving the spreads: the consequences of the catastrophic events, the seasonality and the diversification effects between some different risks are highlighted.
\end{abstract}

Keywords: insurance linked securities, cat. bonds, market price of risk.

JEL classification: G10, G12, G14

${ }^{*}$ Corresponding author. Axa, 9 avenue de Messine, 75008 Paris and Paris School of economics, CES-MSE, Université Paris 1 Panthéon Sorbonne, 106/112 Boulevard de l'Hôpital, 75647 Paris Cedex 13. Email: mathieu.gatumel@axa.com and mathieu.gatumel@gmail.com, Tel : +33 140755751.

${ }^{\dagger}$ Paris School of economics, CES-MSE, Université Paris 1 Panthéon Sorbonne, 106/112 Boulevard de l'Hôpital, 75647 Paris Cedex 13. E-mail: dguegan@univ-paris1.fr., Tel : +33 144078298. 


\section{Introduction}

The insurance securitization has considerably changed for the past three years. This transformation affected not only the different structures allowing the risk transfer to the financial market but also the diversity of the traded risks or the volume of the transactions. Thus while during about ten years the securitization was mainly driven by the insurance linked securities, the insurance loss warranties, the catastrophe swaps or the contingent capital, some new products appeared both in 2005 and in 2006. If the Chicago Mercantile Exchange launched the futures on hurricanes on March, 12. 2007, other products like the Collaterized Debt Obligations of insurance risks or the side-cars appeared. According to us two reasons explain this phenomenon. First of all it seems that the last years relaunched the need of capital capacity, which was already the reason of the birth of the insurance securitization in the 90's. So both the cedants and the investors were looking for new solutions to attract capital. Simultaneously these actors were trained in the securitization modalities, avantages and drawbacks through the first issues. In addition the market is also characterized by the issue of new types of risks. If initially only the sinistrality risks were transfered to the markets through the securitization, the sphere expands in two ways. Firstly the traditional ceded risks, like hurricanes or earthquakes, evolve because they concern other regions like Australia or Mexico and other risks, not only the catastrophic ones but also, for example, mortality. For example the vita risk is now ceded to the market. But it is still a sinistrality risk. Secondly the balance sheet risks are from now on ceded. That means that some cedents use the insurance linked securities in order to reduce their need of capital: the Embedded Value, XXX or AXXX and motor securitization are some examples of this new kind of recourse to the market.

Surprisingly the academic litterature about the insurance derivative market is quite limited. A good survey is done in Mürmann (2001). Among the different theoritical works we can for example cite Cummins and Geman (1993), Geman and Yor (1997), Aase (1999) and Christensen (1999). In the heart of the underlying problems is the central question about how to treat with the incomplete market in the case of the insurance risks. More precisely in terms of insurance linked securities, both Tilley (1998) and Cox and Pedersen (2000) follow a methodology closed to Duffie and Singleton (1999), developped for the defaultable corporate bonds. In terms of papers based on market data, the articles are quite limited too, but we can cite Lane and Movchan (1998) in the case of insurance options, or Bantwal and Kunreuther (1999) and Froot and Posner (2000) who study why the insurance linked securities were not so attractive for the investors, although they were characterized by a high yield spread. In other words they want to understand the different components of these spreads. In particular Froot and Posner (2000) test the consequence of the uncertainty on the spread level. It seems that any detailed 
academic analysis of the secondary markets of the insurance linked securities does not exist. For example the links between the insurance and reinsurance industry, the events which occur and the market are never presented. Moreover the main elements of the insurance linked securities valuation are not highlighted. In this paper we describe several models permitting to study the insurance linked securities market, fulfuilling a gap observed in the known litterature. From exhaustive datasets, we give information concerning the market price of risk and the insurance linked securities.

The paper is organized as follows. Section 2 presents some stylized fact we can observe in the secondary market. Section 3 develops three different methodologies which allow to capture an implicit market price of risk of the insurance linked securities (ILS). In Section 4, we provide some empirical results and Section 5 concludes.

\section{Market behaviour}

Since 2004 Swiss Re provides us weekly data concerning the bid and offer prices of some insurance linked securities issues and the corresponding discount rates, that we presents below. We define the discount rate like the rate which gives the bid and ask prices. Now, let $P_{i O}$ and $P_{i B}$ be the offer and bid prices of the insurance linked securities $i, y_{i O}$ and $y_{i B}$ the corresponding offer and bid spreads and $r$ the risk-free rate. Then, we define:

$$
\begin{aligned}
P_{i O t} & =\sum_{j=t+1}^{T} \frac{F_{j}}{\left(1+r_{j}+y_{i O j}\right)^{T-j}}, \\
P_{i B t} & =\sum_{j=t+1}^{T} \frac{F_{j}}{\left(1+r_{j}+y_{i B j}\right)^{T-j}},
\end{aligned}
$$

with $F_{j}$ the paiement at time $j$ at the bondholder - coupon and/or repayment of the principal - and $T$ the maturity of the issue.

Practically the spreads appearing in (1) and (2) are expressed following an annual form. Thus, one needs to modify them in these previous formulae in order to correspond to the real discounting period. Moreover to obtain the exact price of the ILS, it it also necessary to take into account the cum dividend between the date at which the last coupon is paid and the observation date. The risk-free rate generally used is the Libor three months, because most of the insurance linked securities paid a coupon over Libor every quarter.

Considering on the one hand the bijective link between the prices and the spreads and on the other hand the traditional practices, we will only study the spread behaviour to characterize the 
ILS. Moreover knowing that the difference between the offer and bid spreads is only due to the remuneration of the intermediary, we will only study the bid spread that we call "spread", and we denote it, from now, $y_{i t}$, for the issue $i$ at timet.

On December 31st 2006 at least 72 issues are regularly traded on the market. We choose to aggregate their spreads by building an index whose modalities are the following:

- The index starts on January 1st 2004 with a value of 100.

- All the issues have the same weight. This means that their weight in the index does not depend on the amount issued.

- On January 1st 2004, all the spreads in the market have the same value, 100.

- At each date, every week, the index of each issue is adjusted, depending on the spread behavior.

- The index value of new issues is equal to the value of the market index, as if they were not introduced.

- The market index is the mean of all the indices.

Thus, the value of the index at time $t$ for the issue $i, I_{i t}$, is given by the following expression:

$$
I_{i t}=I_{i t-1} \times \frac{y_{i t}}{y_{i t-1}},
$$

with $I_{0}=100$. The value of the market index at time $t$ is the mean of the values of the individual indices at this date:

$$
I_{t}=\frac{1}{n_{t}} \sum_{i=1}^{n_{t}} I_{i t},
$$

with $n_{t}$ the number of traded issues at time $t$ on the market.

Finally several spread analysis levels are possible: per issuer, intermediary, covered zone or risk traded. We study the spread behaviour in two ways. First of all we observe it on the global market . Then we analyse it following the traded risk. It is equivalent to consider the spreads risk per risk: for all the risks - European windstorm, hurricanes, Californian earthquakes, Japan Earthquakes, etc. - an index, similar with the previous one, is built. This analysis allows to capture the "underlying risk" as a decisive factor in the spread level.

The figure 1 shows the evolution of the market index $I_{t}$ since January 1st 2004. It is possible to point out that the spreads are considerably volatile, the index growing to 100 in January 2004 by 140 in June 2007, with a peak closed to 160 in August 2006. 


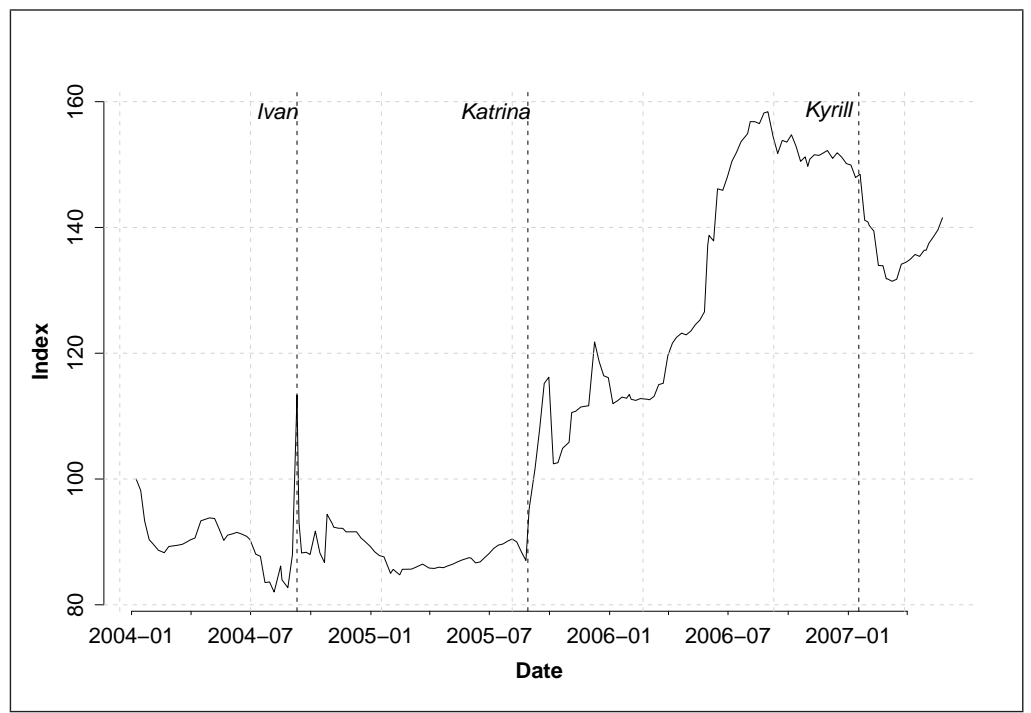

Figure 1: ILS Spread index, $I_{t}$, since January 1st 2004 until June 30th 2007.

It is possible to distinguish three periods during the three last years. The first one starts January 1st 2004 and ends in August 2005. It is characterized by a relative decrease of the spreads: the decrease is close to $13 \%$, the index going to 100 by 87.05 , with a minimum of 82.72 on August 27th 2004. The period contains also a spread explosion in September 2004, the spread index is equal to 113.35 on September 10th 2004 (explosion due to three hurricanes which hit the USA). We can note that this last explosion does not cause a jump of the spreads: those rose before decreasing.

The hurricanes in 2004 have an impact on the cat. bonds market. They appear very different from the one due to Katrina in August 2005, which seems to affect durably the market and characterizes the beginning of a second period. Indeed, if in 2004 we observe an explosion instead of a jump, in 2005 the spreads after an increase do not decrease until their initial level. The ILS spread index is equal to 87.05 just before the jump and 102.42 on October 7th 2005 . This last level increases again in November and December 2005. The spreads are at the top on December 9th, with an index that is equal to 121.80. This hurricane, which did between $\$ 40$ and $\$ 60$ billions of damages to the insurance industry seems to have changed durably the insurance linked securities market, whatever the peril covered by the issues. Several reasons can be given:

- Katrina causes the first default of a cat. bond, in the event the one of Kamp Re;

- the extent of the catastrophe can modify the perception of this kind of risk by the investors, strengthening their aversion.

More generally this second period is characterized by a second increasing trend, highly visible from February 2006. A very high but non sudden increase can be noted, between 10th February 
2006 and August 31st the index taking $40 \%$ - it goes to 112.60 by 158.40 - before decreasing to the 130 level. The main reasons come from the avian influenza which reinforced the pressure on the ILS market covering the mortality risk and the anticipation of a very active hurricane season. A lot of analysts have anticipated five or six very strong events during the period. Finally no comparable catastrophe hits the USA and the spectrum of an epidemic diseappered, too. These reasons coupled with the reinsurance market behaviour justify the birth of a third period in the spread evolution. It starts in September 2006 and goes at least to March 2007. From the initial level of 158.40 the spreads fell to 130 before increasing again.

The three sub periods allow to identify two factors driving the spreads in the insurance linked securities market. The first one is the seasonality of some risks. For example, the US or European windstorm risk is not uniform throughout the year but the spread to investors is earned over an annual period. So the spreads rise as the market moves into US or European windstorm season to compensate the wind risk that the investors are taking and then decline as the market get towards the end of the season. This is why both March 2006 and March 2007 are characterized by a reversal of the spreads due to the approach of the hurricanes season. As the risk becomes stronger, the risk premium rises. Maybe due to the non maturity of the market, this phenomenon is not present in 2004 and in 2005.

The second factor is the risk aversion and the investor demand. The jump of the spreads during the fourth quarter of 2005 is due to an increase of the risk aversion and a need for the issuers to raise capital in order to transfer their risk. For instance, Katrina maybe modifies the risk perception by the investors and the need of capital reinforces the tensions in the market. On the contrary the decrease of the spreads in 2007 is mainly due to the substantial increase of the investor capacity. The same phenomenon is observable at the beginning of 2004 until hurricane Katrina. The tightening of the spreads is due to the increasing number of investors interested in the insurance linked securities.

Moreover all the catastrophic events have not the same consequences on the insurance linked securities market. If the events of August 2005 and 2006 led to some movements on the spreads, some movements are not directly reliable to catastrophic events or some catastrophic events have no impact on the market. For example even if the European windstorm Kyrill led to an event notices for two bonds (Aïolos and Eurus), the consequences in the secondary market were quite non-existent: the index went from 147.98 to 148.46 before decreasing to 141.15.

The figure 2 describes the spread evolution of three cat. bonds: Aïolos, Pylon Ltd. B and Redwood VII. To put forward some characteristics of the spreads on the secondary market, we chose two issues covering the same risk, the European windstorm, Aiolos and Pylon Ltd. 
B, whereas the Redwood VII issue covers the Californian earthquakes. On the figure 2 the horizontal lines stands for the original coupon of the issues.

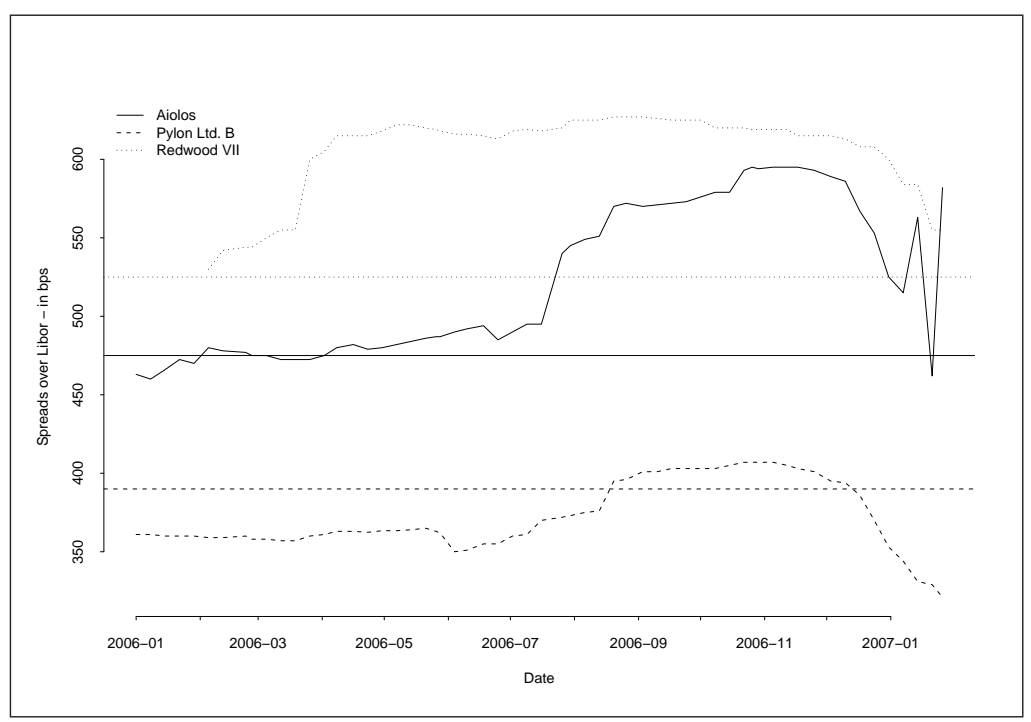

Figure 2: Spreads evolution of the Aiolos, Pylon Ltd. B and Redwood VII issues since the 1st January 2006.

First of all we can put forward that in the secondary market, the spreads are more or less around the original spreads of the issues, in particular for the Pylon Ltd. B case. Then the insurance linked securities covering the same risk have a very similar behavior. We can distinguish three phases for the Aiolos and Pylon Ltd. B spreads. Between January and June 2006, the spreads are globally flat before rising until November 2006. The end of the time interval is characterized by a decreasing of the spreads. Aïolos is more volatile than Pylon Ltd. B, during this period. It is interesting to point out that the event notice on Aïolos in January 2007 induces a high volatility on the spreads. The same phenomenon would be also visible with Eurus, another issue characterized by an event notice. On the other hand the behavior of the Redwood VII issue is a little bit different. After the issue the spreads are characterized by an increasing and they are then quite flat until the end of 2006.

This analysis shows that three factors drive the spread behavior on the insurance linked securities secondary market:

- a common factor which allows to include in the model the influence of systematic risk like a catastrophe or a change in the investors' behaviour;

- a risk specific factor, which allows to take into account the specificity of each traded risk like the seasonality of the European windstorm or the hurricanes;

- and an issue specific factor. 
The highlight of the covered risk as explanatory variable pushes to study the behaviour of the index of some risks. The figure 5 represents such an index. First of all, it allows to point out that three risks seem to drive the market: the US windstorm, the Californian eartquake and the European windstorm. Knowing that they correspond to the majority of the issues, the level of their spreads is driving the spreads of the market as a whole. Then following the index level of each risk, it appears that the spreads which have the bigger increase are those relative to the Californian earthquake with a long period during which the spreads are above 140. On the contrary the lower spreads are those of the issues covering the Pacific earthquake: the diversification they represent in the portfolio could maybe explain this phenomenon.

Remark 1. The importance of the diversification effect as explanatory factor of the coupon level can be pointed out with the Australis issue on the one hand and Successor Euro Wind Class B-I issue on the other hand: the expected loss are respectively 210 and 209 bps whereas the coupons are 400 against 700 bps. The only difference lies on the covered risk: the Australis issue is relative to the wind and earthquakes in Australia whereas the Successor Euro Wind Class B-I issue is relative to the European windstorm.

The periods previously identified appear more or less clearly, depending on the studied risk. Thus, the period beginning January 1st 2004 and ending just before the Katrina presents the same characteristics at the market level or at the considered risks level: the spreads decrease sligthly. Nevertheless a real difference appears depending on the risks. The issues covering the US hurricanes are all characterized by a spreads' peak in September 2004. But this peak is not observed for the other ones. It is the consequence of the hurricanes which hit the US this month. On the other hand, one year later, all the issues are affected by Katrina: for all the risks the spreads are characterized by a strong increase. In addition the seasonality component of the spreads is highly visible. For example the issues covering the European windstorm have their spreads which increase immediately after Katrina and also in November and December 2005, due to the future windstorm season, but just after they decrease. On the contratry spreads on Pacific or Californian earthquakes increase as far as August 2006, illustrating certainly the change in risk aversion previously identified. It is interesting to point out the presence of a peak in the secondary markets for all types of risk in December 2006. It is maybe a second shock due to Katrina. Let us note that the Atlantic and Western Re program was issued in November 2005 at a very high price, according to its risk level. Thus, the increase of the spreads in the secondary market could be the transfer to this market of the phenomenon observed at this issue.

The returns described in this section are the remuneration required by the investors. They aim to compensate the risks they are taking by buying the insurance linked securities. But, if a first component of the spreads can be captured by the expected loss of each issue, the required 
coupon integrates someother elements. Thus, an important part of the spread is unexplained. The goal of the next section is to put forward this unexplained component. Three kinds of works deal with the understanding of the market price of the insurance linked securities risk. There are the model of Lane Financial LLC (2003), the model of Fermat Capital Management (2005) and the model of Wang (2004). We firstly present the different methodologies, then the models are estimated on the coupon at the issue in 2006 and the estimation will be done with the data of the secondary market. A discussion follows.

\section{Analysis of the spreads components}

The Lane Financial LLC model The Lane Financial LFLLC model (Lane (2000), Lane (2003) and Lane and Beckwith (2003)), is the first model which has been developped to understand the behaviour of the cat. bonds' market. It is the unique model which tries to link the obtained results on the cat. bonds markets and those obtained on the reinsurance market. This model can be presented as follows:

$$
Y_{i}=X_{i}+\gamma \times V_{i}^{\alpha} \times Z_{i}^{\beta},
$$

where: $\quad Y_{i}$ is the spread over the risk-free rate of the issue $i$;

$X_{i}$ is the expected loss;

$V_{i}$ is the Probability of First Dollar Loss, PFL;

$Z_{i}$ is the Conditional Expected Loss, CEL;

$\theta=(\alpha, \beta, \gamma)$ is a vector of "shape parameters".

This model assumes that the main determinant of the spread is the expected loss: $Y_{i}=f\left(X_{i}\right)$. Knowing that $X_{i}=V_{i} \times Z_{i}$, the equation (5) permits to give a weight different for each component of the expected loss.

In order to take into account the presence of heteroscedasticity we consider an extension of the model (5) in the following way:

$$
\begin{cases}\ln \left(Y_{i}-X_{i}\right) & =\ln (\gamma)+\alpha \ln \left(V_{i}\right)+\beta \ln \left(Z_{i}\right)+\epsilon_{i} \\ \epsilon_{i}^{2} & =\xi \times \sigma_{i} \\ \sigma_{i}^{2} & =E\left[\epsilon_{i}^{2} \mid \mathcal{T}_{i}\right]\end{cases}
$$

where $\xi$ is a strong white noise and

$$
\sigma_{i}^{2}=\xi \times \frac{1}{\exp \left\{\ln \left(V_{i}\right)\right\}} .
$$


In order to apply this model on our datasets, the parameters are estimated using least squares method.

The Fermat Capital Management model Starting from the observation that the insurance linked securities offer a very high expected return compared to the other assets, Fermat Capital Management develops another model assuming that the Sharpe analysis built in the financial market is not relevant for these assets. So the traditional analysis in terms of $(\alpha, \beta)$ have been replaced by an analysis in terms of $\left(\alpha_{\text {exotic }}, \beta_{\text {exotic }}\right)$, where exotic stands for the insurance linked securities market. In other words the traditional functional form

$$
E\left(R_{i}\right)=\alpha+\beta M P R_{i},
$$

where: $E\left(R_{i}\right)$ is the expected return of the stock i,

$M P R_{i}$ is the financial market price of risk,

is transformed into a Catastrophe Asset Pricing Model, which considers the Rate on Line of the insurance linked security $i$ in the following form:

$$
Y_{i}=X_{i}+\beta \times M P R_{i},
$$

where: $Y_{i}$ is the Rate on Line or, more commonly, the spread,

$X_{i}$ is the expected Loss,

$\beta=\frac{1}{\sqrt{m_{i}}}$, with $m_{i}$ the weight of the risk covered by the issue $i$,

$M P R_{i}=\lambda \times \sqrt{X_{i} \times\left(1-X_{i}\right)}$,

$\lambda$ is the Sharpe Ratio, according to Fermat Capital Management.

In other words $\left(\alpha_{\text {exotic }}, \beta_{\text {exotic }}\right)$ are determinated in a referential which allows to take into account the specificities of the insurance linked securities market with the form of $M P R_{i}$. The introduction of $m_{i}$ allows to capture the diversification phenomenon on the market through the model and corresponds to the rank of the risk covered by the issue $i$ in this classification. For example, the Florida hurricanes are certainly the more important risk in terms of insurance exposure: so, $m_{i}$ equals 1 for the issues covering this risk. If the European windstorm is the sixth exposure, $m_{i}$ equals 6 . Hence, the higher is $m_{i}$, the higher will be the market price of risk. Knowing that the expected loss is not reliable to the weight of the risk, the model assumes that the higher is the exposure of the industry to a risk, the higher will be the expected return of an issue covering this risk.

In order to take into account the heteroscedasticity, the model (9) is transformed as: 


$$
\begin{cases}Y_{i} & =X_{i}+\lambda \times \frac{1}{m_{i}} \times \sqrt{X_{i}\left(1-X_{i}\right)}+\nu_{i} \\ E\left[\nu_{i}\right] & =\bar{\nu} \\ V\left[\nu_{i}^{2}\right] & =\sigma^{2} \times \exp \left\{x_{i}^{\prime} \alpha\right\}\end{cases}
$$

where $\left(\nu_{i}\right)$ is a sequence of independant and identically distributed variables. The least squares methodology is also used to estimate the parameters.

The Wang (2004) model is based on a methodology which allows to price reinsurance layers. Let $L$ be a random underlying loss variable and $L_{(a ; a+h]}$ a variable corresponding to a layer with limit $h$ and attachment point $a$. Then:

$$
L_{(a ; a+h]}=\left\{\begin{array}{lll}
0 & \text { if } \quad L<a \\
L-a & \text { if } \quad a \geq L<a+h \\
h & \text { if } \quad L>a+h .
\end{array}\right.
$$

The expected loss of the layer is equal to the area under the loss exceedance curve. If $X(l)=$ $P(L>l)$, over the interval $(a, a+h]$, then:

$$
E\left[L_{(a ; a+h]}\right]=\int_{a}^{a+h} X(l) d l .
$$

The layer price often contains a risk load in addition to the expected loss. Wang (2004) uses the probability transforms to extend the concept of the Sharpe ratio to the asymetric distributions and to valuate the risk adjusted performance of the insurance linked securities. Then, he defines:

$$
X^{\star}(l)=\Phi\left(\Phi^{-1}(X(l))+\lambda\right)
$$

where $\Phi$ represents the standard normal cumulative distribution, $\lambda$ is a direct extension of the Sharpe ratio, the mean value under $X^{\star}(l)$ defines a risk-adjusted "fair-value" of the ILS.

Moreover, to incorporate the parameter uncertainty and the behaviour of greed and fear, he suggests to use in the relationship (12) a Student-t distribution in place of $\Phi$ :

$$
X^{\star}(l)=\mathcal{Q}\left(\Phi^{-1}(X(l)+\lambda)\right)
$$

where $\mathcal{Q}$ is a Student-t distribution with degree of freedom $k$. The model is estimated with the traditional maximum likelihood estimation methodology. 


\section{Some empirical results}

\subsection{Determination of the market price of risk, at the issue}

In this section, we apply the previous models on some datasets and compare their performance. We observe $X_{1}, \ldots, X_{N}, V_{1}, \ldots, V_{N}, Z_{1}, \ldots, Z_{N}$ and $Y_{1}, \ldots, Y_{N}$, representing respectively the expected loss, the probability of the first dollar loss, the conditional expected loss and the spreads of the $N$ issues. Considering the fact that Katrina transformed durably the market, the estimations are done for the ILS issued between January 1st 2005 and August 31st2005, September 1st2005 and December 31st 2005 and January 1st 2006 and December 31st 2006.

Lane Financial LFLLC Results The results of the Lane Financial LFLLC Results are provided in table 1 . In summary all the parameters increase after Katrina: $\ln (\gamma)$ rises from -1.796 to -0.912 (consequently $\gamma$ rises from 0.166 to 0.402 ); $\alpha$ rises from 0.332 to 0.424 and $\beta$ from 0.086 to 0.268 . They allow to conclude that the hurricane Katrina caused a major change in the insurance linked securities market as it was previously observed, the investors requiring a higher return in order to buy the risk. The market price of risk rises, both just after Katrina and also in 2006. It is important to point out the importance of the standard error of the parameter $\beta$. At the $5 \%$ threshold, this coefficient is not significative. It is not the case for the other parameters.

\begin{tabular}{lccc}
\hline \hline & $2005-01-01$ & $2005-09-01$ & $2006-01-01$ \\
& $2005-08-31$ & $2005-12-31$ & $2006-12-31$ \\
\hline $\ln (\gamma)$ & -1.796 & -1.031 & -0.912 \\
$\alpha$ & $(0.099)$ & $(0.565)$ & $(0.198)$ \\
$\alpha$ & 0.332 & 0.406 & 0.424 \\
$\beta$ & $(0.024)$ & $(0.127)$ & $(0.050)$ \\
& 0.086 & 0.764 & 0.268 \\
& $(0.174)$ & $(0.867)$ & $(0.251)$ \\
\hline
\end{tabular}

Table 1: Results of the Lane Financial model.

Fermat Capital Management Results The table 2 summarizes the results of the Fermat Capital Management model and highlights the same elements as before. The model's parameter is time two bigger just after the hurricane Katrina and increases in 2006.

\begin{tabular}{cccc}
\hline \hline & $2005-01-01$ & $2005-09-01$ & $2006-01-01$ \\
& $2005-08-31$ & $2005-12-31$ & $2006-12-31$ \\
\hline$\lambda$ & 0.365 & 0.544 & 0.694 \\
\hline
\end{tabular}

Table 2: Results of the Fermat Capital Management model. 
Wang Model Results The results of the Wang model point out additional information comparing with the other models. Indeed Katrina does not only induce an increase of the market price of risk but induces also an increase of the uncertainty, captured by the parameter $k$, which is the number of degrees of freedom of the Student-t distribution.

\begin{tabular}{cccc}
\hline \hline & $2005-01-01$ & $2005-09-01$ & $2006-01-01$ \\
& $2005-08-31$ & $2005-12-31$ & $2006-12-31$ \\
\hline$\lambda$ & 0.486 & 0.628 & 0.705 \\
$\mathrm{k}$ & 21.716 & 15.170 & 11.100 \\
\hline
\end{tabular}

Table 3: Results of the Wang model.

The figure 3 provides the observed and estimated spreads with the three models. We note that the three models are able to capture the spreads in the primary market: all the estimated coupons are more or less closed to the real coupons. Moreover the models highlight the common factor which drive the market price of risk. Indeed, when a model sub or over estimates the coupon, we observe the same fact for the other models.

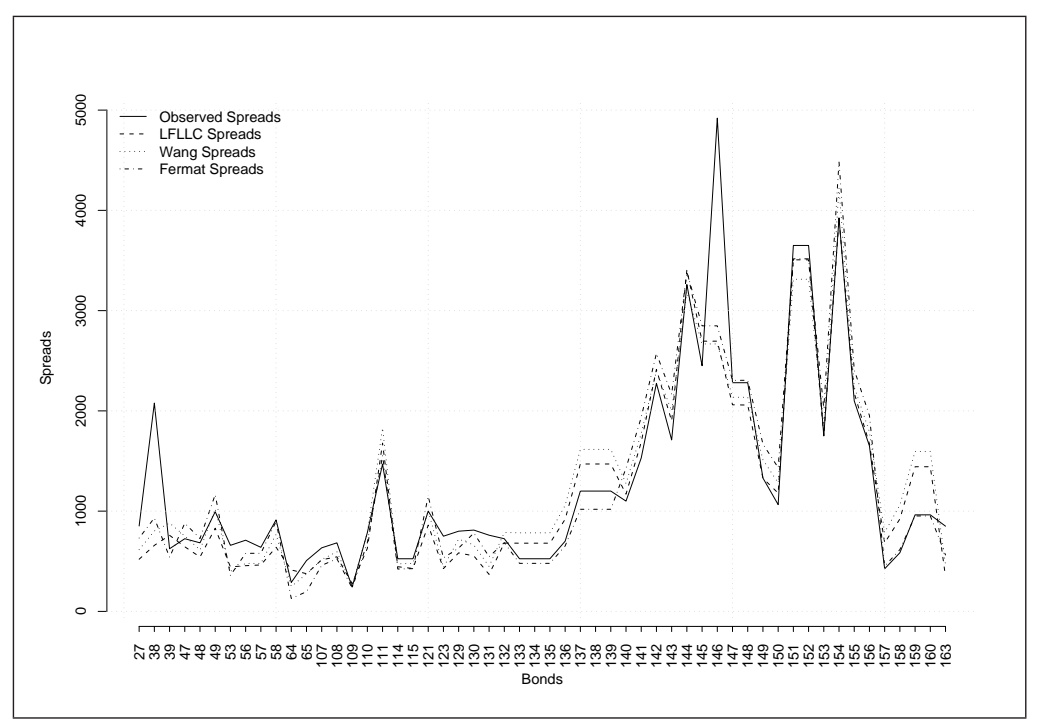

Figure 3: Relevance of the Wang, Lane Financial and Fermat Capital Management models

\subsection{Temporal analysis}

\subsubsection{Analysis of the market as a whole}

We adapt now the previous models to the secondary market. Until now we dit not consider any particular form of the dependency between the spreads. Nevertheless the spread of each issue can be driven by its previous level and some risks (like the US hurricanes) can drive the market 
as a whole. We introduce inside the previous models some dynamics depending on time using an $A R(p)$ process.

The Wang model becomes:

$$
\left\{\begin{aligned}
Y_{i t} & =Q\left(\Phi^{-1}\left(X_{i}\right)+\lambda_{t}\right)+u_{i t} \\
u_{i t} & =\bar{u}_{t}+\sum_{j=1}^{p} \phi_{i j}^{1} u_{i t-p}+\nu_{i t}
\end{aligned}\right.
$$

where $Y_{i t}$ is the spread of the issue i at time $t$ on the secondary market, $Q$ has a Student-t distribution with $k_{t}$ degrees of freedom, $X_{i}$ is the expected loss of the issue i, $\lambda_{t}$ is the Sharpe ratio at time $t, t=1, \ldots, T$. The study is conducted between January 1 st 2004 and December 31st 2006, the process $\left(u_{i t}\right)$ is an $A R(p)$ process such that $E\left(u_{i t}\right)=\bar{u}_{t}, \nu_{i t}$ is a Gaussian white noise $N\left(0, \sigma^{2}\right)$.

In the same way, the Lane Financial model becomes:

$$
\begin{cases}\ln \left(Y_{i t}\right) & =\ln \left(\gamma_{i t}\right)+\alpha_{t} \ln \left(V_{i}\right)+\beta_{t} \ln \left(Z_{i}\right)+\epsilon_{i t} \\ \epsilon_{i t} & =\bar{\epsilon}_{t}+\sum_{j=1}^{p} \phi_{i j}^{2} \epsilon_{i t-p}+\omega_{i t}\end{cases}
$$

where $Y_{i t}$ is the spread of the issue i at time $t$ on the secondary market, $V_{i}$ and $Z_{i}$ are respectively the probability of first loss and the conditional expected loss, the process $\left(\epsilon_{i t}\right)$ is an $A R(p)$ process such that $E\left(\epsilon_{i t}\right)=\bar{\epsilon}_{t}$, and $\omega_{i t}$ is a Gaussian white noise $N\left(0, \sigma^{2}\right)$.

Lastly, in the case of the Fermat Capital Management model, we have:

$$
\left\{\begin{aligned}
Y_{i t} & =X_{i}+\lambda_{t} \times \frac{1}{m_{i}} \times \sqrt{X_{i}\left(1-X_{i}\right)}+\xi_{i t} \\
\xi_{i t} & =\bar{\xi}_{t}+\sum_{j=1}^{p} \phi_{i j}^{3} \xi_{i t-p}+\vartheta_{i t}
\end{aligned}\right.
$$

with $Y_{i t}$ the spread of the issue i at time $t$ on the secondary market, $\lambda_{t}$ the Sharpe ratio at time $t, m_{i}$ is the weight of the risk traded by the issue $i$, the process $\left(\xi_{i t}\right)$ is an $A R(p)$ process such that $E\left(\xi_{i t}\right)=\bar{\xi}_{t}$ and $\vartheta_{i t}$ is a Gaussian white noise $N\left(0, \sigma^{2}\right)$.

We do not assume a particular form for the variance-covariance matrices at first but, we estimate the temporal Lane Financial and Fermat Capital Management models using the seemingly unrelated regressions (SUR) procedure to improve estimation efficiency by allowing for cross equations correlations among the regression error terms. The temporal Wang model is estimated by a repetition of maximum likelihood estimations date after date.

In order to take into account the issues which appear regularly in the secondary market, it is not possible to conduct only one analysis between January 1st 2004 and December 31st 2004. So the sample of issues allowing the estimation of the different models is actualised every four months. 
We assume that this delay allows to extract some elements of the form of the dependence both in time and between different issues.

\subsubsection{Parameters evolution}

The figure 4(a) shows the evolution of the Wang parameters' model. If we exclude the very high volatility of the parameters, the graph highlights the close evolution of the two parameters. This close evolution between the market price of risk and the number of degrees of freedom means that this last model is irrelevant to show that the lower is the uncertainty (characterized here by $k$ ), the greater is the risk premium (characterized here by $\lambda$ ). Thus it seems that the Wang (2004) model cannot explain the evolution of the market price of risk.

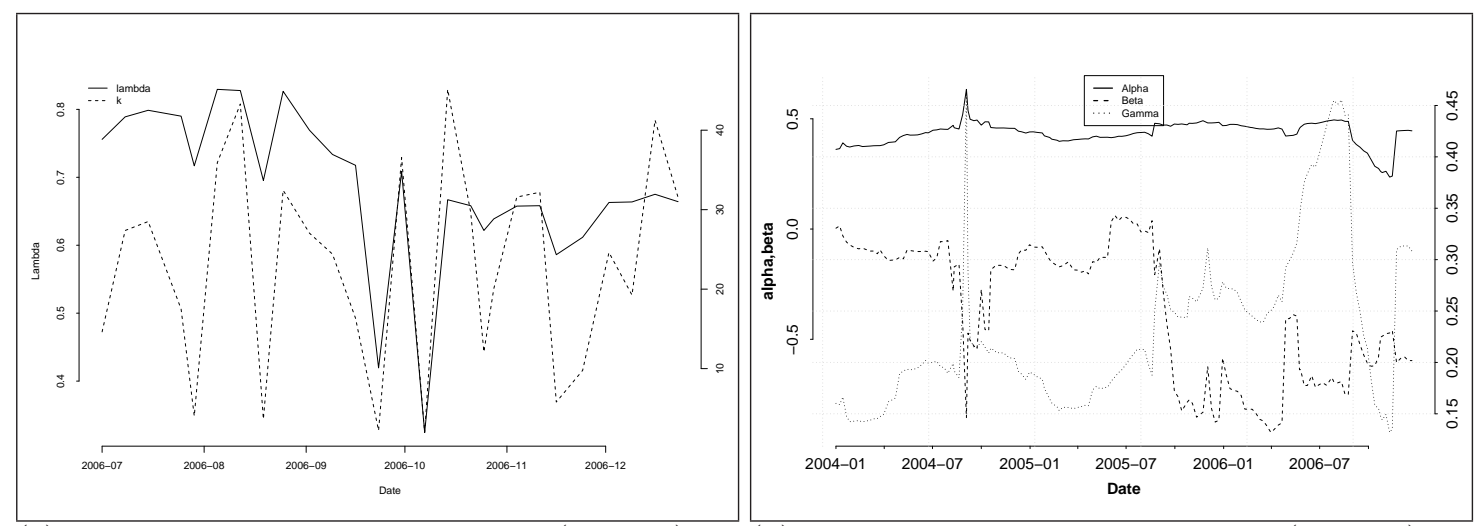

(a) Evolution of the Wang parameters $(\lambda$ and $k$ ) be- (b) Evolution of the Lane parameters $(\lambda$ and $k)$ between 1st January 2006 and 31st December 2006, tween 1st January 2004 and 31st December 2006, using equation (14). The vertical left axis stands for using equation (15). The vertical left axis stands for $\lambda$, the verical right axis for $k$. $\alpha$ and $\beta$, the vertical right axis for $\gamma$.

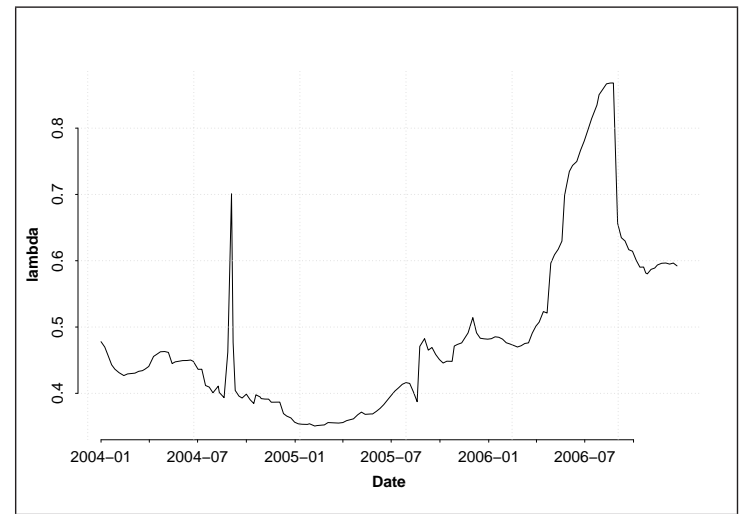

(c) Evolution of the Fermat parameter between 1st January 2004 and 31st December 2006, using equation (16).

Figure 4: Evolution of the parameters for the Wang, Lane Financial and Fermat Capital Management model. 
The evolution of the Lane parameters $(\alpha, \beta, \gamma)$ is represented on the graph $4(\mathrm{~b})$. The detailed results are given in the tables $4-6$. Two main underlying behaviours of the market can be highlighted. First of all a structural component is captured by $\alpha$ and $\beta$ (the elasticities to the probability of first loss and to the conditional expected loss). For example the changes due to the hurricanes in September 2004 and in August 2005 are characterized by a peak and a jump of $\alpha$. The hurricanes Frances, Ivan and Jeanne did not induce some structural changes, as in 2005 with Katrina (see also the figure 1). The anticipation of the future hurricanes season induces an increase of $\alpha$ in May and June 2006. The decrease of this parameter accross the last quarter of 2006 highlights the fact that the decrease of the spread is not only due to the end of the hurricane season but also to a change of the investor behaviour. Following the fact that the evolution of $\gamma$ is very closed to the evolution of the index, we can interpret $\gamma$ as the parameter which captures the conjonctural component of the spread behaviour.

The Fermat model contains only one parameter. Thus, this one clearly replicates the market evolutions (see figures 1, 4(c) and table 8) and is very close but less volatile than the $\gamma$ parameter of the Lane model. The structural and conjonctural components cannot be isolated.

The results corresponding to the time series part of the temporal Lane and Fermat models are summarized in Tables 7 and 9. It is possible to see that their autoregressive parts are quite similar. Most of the issues are characterized by an $A R(1)$ process and the results are quite stable accross the different sub periods. When the order varies, from an $A R(p)$ to an $A R(q)$, we often have $q>p$, indicating a growth of the dependence of the spreads between the present time and the past. We can also assume that $\Phi_{1}^{2}$ increases between May 1st 2005 and May 1st 2006 but the trend is not very clear. We can interpret these results in two ways. First of all they can highlight the fact that the market is characterized by non maturity because the last event drives the market without considering the previous ones. Second we can assume that the market is very mature in the sense that the prices reveal all the information.

\subsubsection{Analysis Risk per Risk}

The previous analysis is also done for the following issues : issues covering the US Wind (W-US), European Wind (W-EUR), US wind and earthquakes (W,Q-US) and Californian earthquakes (Q-CA). The results are given in Table 6. They are quite similar to those obtained for the whole market. The parameters $\alpha$ and $\beta$ correspond to structural parameters, specially for W, QUS and W-EUR (risks which are driving the market behaviour), whereas $\gamma$ and $\lambda$ capture the conjonctural movements of the market. More precisely this analysis illustrates the diversification effect included in the required return, through the value of $\lambda$. In figure 6 , it appears that $\lambda$ is 
higher for the mortality risk and lower for US windstorm. But if we consider not only $\lambda$ but the vector $(\lambda, \beta)$, here $\beta$ incorporates the weight of the exposure. It appears that the market price of risk is higher for US hurricanes, which is the highest exposure of the insurance industry. Concerning the Lane Financial model parameters, we note that $\alpha$ has quite the same value whatever the risk but it is more volatile for the Californian earthquake or the mortality risk. It appears difficult to interpret the value of $\beta$, specifically for the Mortality risk.

\section{Conclusion}

The recourse to the insurance linked securities has considerably changed for the past two years and the spreads reflect this evolution. In this paper we highlight both a structural component, the risk aversion of the investors, and a conjonctural component, for example the seasonality of the hurricanes, driving the spreads. Some risks, like US hurricanes, European windstorms or Californian earthquakes, have a strong impact on the market and appear to be the main determinants of the market price of risk. 


\section{References}

Aase, K. (1999). An Equilibrium Model of Catastrophe Insurance Futures and Spreads. Geneva Paper on Risk and Insurance Theory, 24:69-96.

Bantwal, V. and Kunreuther, H. (1999). A Cat Bond Premium Puzzle? Center for Financial Institutions Working Papers, Wharton School Center for Financial Institutions, University of Pennsylvania, USA.

Christensen, C. V. (1999). A New Model for Pricing Catastrophe Insurance Derivatives. Centre for Analytical Finance, University of Aahrus, Denmark, Working Papers.

Cox, S. and Pedersen, H. (2000). Catastrophe risk bonds. North American Actuarial Journal, $4(4)$.

Cummins, D. and Geman, H. (1993). An Asian Option to the Valuation of Insurance Futures Contracts. Center for financial institutions working papers, Wharton School Center for Financial Institutions, University of Pennsylvania, USA.

Duffie, J. and Singleton, K. (1999). Modeling term structures of defaultable bonds. Review of Financial Studies, 12:687-720.

Froot, K. and Posner, S. (2000). Issues in the Pricing of Catastrophe Risk. Trade Notes, Marsh \& McLennan Securities.

Geman, H. and Yor, M. (1997). Stochastic Time Changes in Catastrophe Option Pricing. Insurance: Mathematics and Economics, 21:185-193.

Lane, M. (2000). Pricing Risk Transfer Transaction. Astin Bulletin, 30(2):259-293.

Lane, M. (2003). Rationale and Results with the LFC Cat. Bond Pricing Model. Trade Notes, Sedgwick Lane Financial.

Lane, M. and Beckwith, R. (2003). How High is Up? The 2006 Review of the Insurance Securitization Market. Trade Notes, Sedgwick Lane Financial.

Lane, M. and Movchan, O. (1998). The Perfurme of Premium II. Trade Notes, Sedgwick Lane Financial.

Mürmann, A. (2001). Pricing Catastrophe Insurance Derivatives. Center for Financial Institutions Working Papers, Wharton School Center for Financial Institutions, University of Pennsylvania and Financial Markets Group, USA.

Tilley, J. (1 July 1998). The Securitisation of Catastrophic Property Risks. Insurance: Mathematics and Economics, 22:299-299(1).

Wang, S. (2004). Cat. Bond Pricing Using Probability Transforms. Geneva Papers: Etudes et Dossiers, Special Issue on "Insurance and the State of the art in Cat. Bond Pricing, 278:19-29. 


\section{Appendices}

Figure 5: Spreads index evolution since 1st January 2004 for some risks.

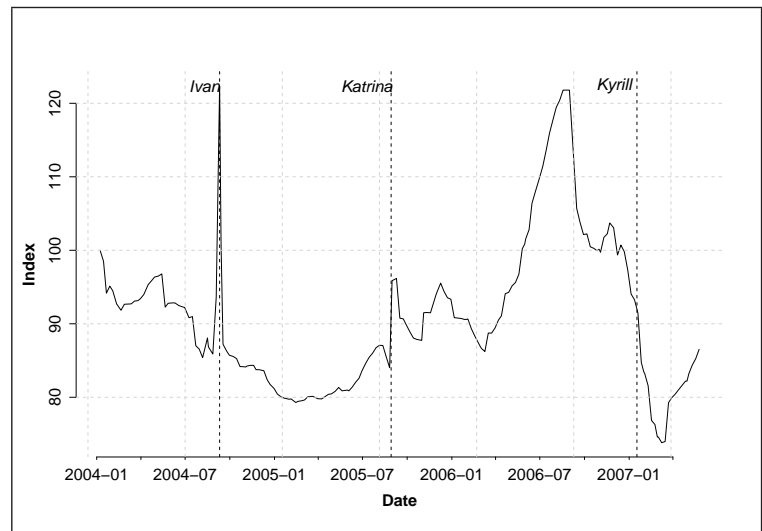

(a) European, US, Californian and Pacific windstorm and earthquakes

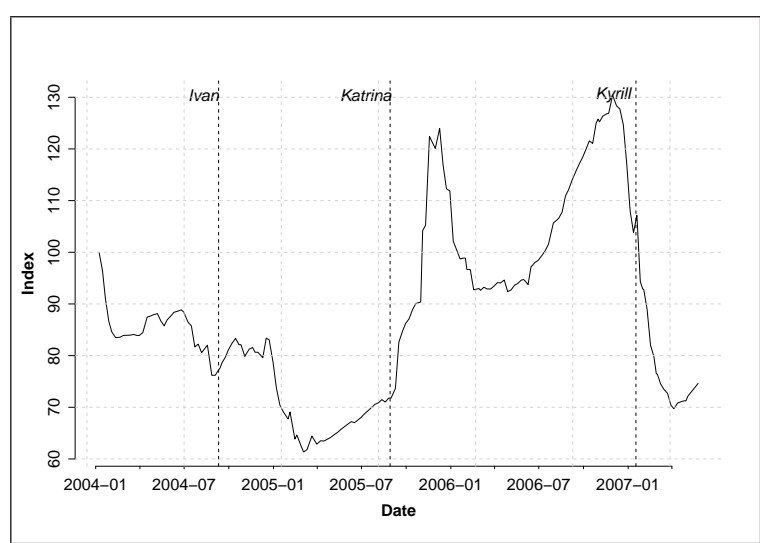

(c) European windstorm

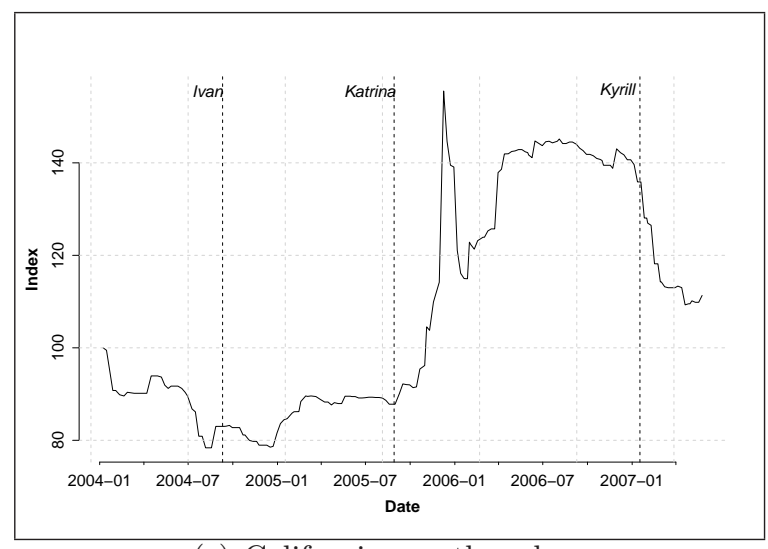

(e) Californian earthquakes

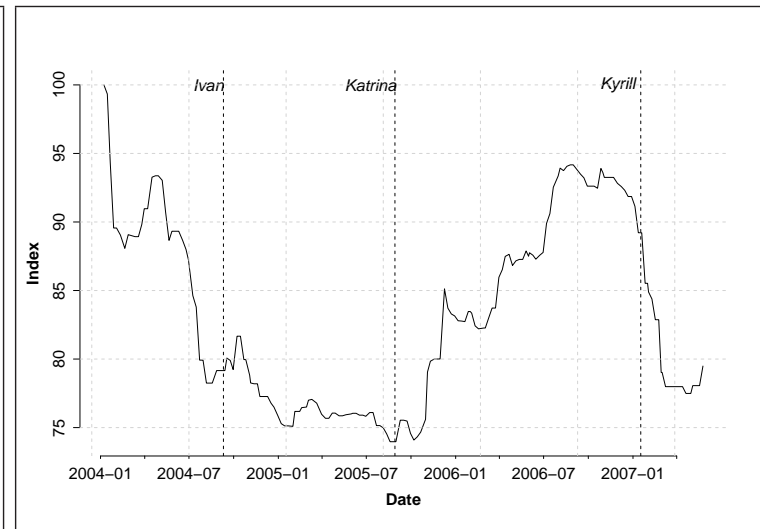

(b) Pacific earthquakes

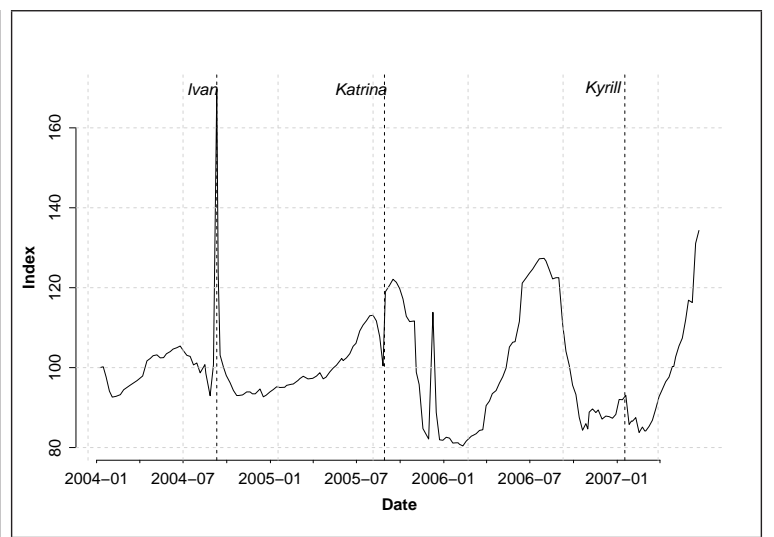

(d) US windstorm

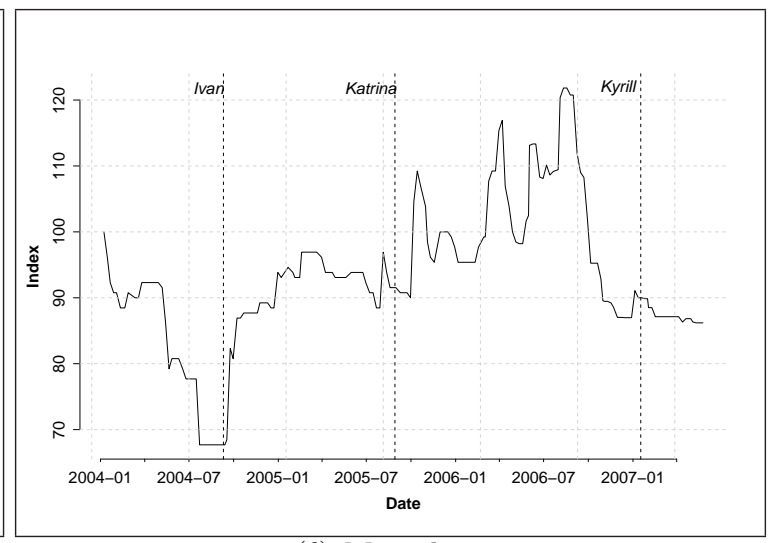

(f) Mortality 
Table 4: Characteristics of the $\alpha$ parameter from the Lane Financial model on the sub period 1st January 2006 - 31st December 2006.

The following table summaries the main statistics relative to the $\alpha$ parameter of the Lane Financial model:

$$
\ln \left(Y_{i t}\right)=\ln \left(\gamma_{i t}\right)+\alpha_{t} \ln \left(V_{i}\right)+\beta_{t} \ln \left(Z_{i}\right)+\epsilon_{i t} .
$$

The estimation was done between 1st January 2004 and 31st December 2006. The regression results of the last year are presented.

\begin{tabular}{|c|c|c|c|c|c|c|c|c|c|c|c|}
\hline Date & Parameter & Std. & Error & t Value & $\overline{\mathrm{P}(>|t|)}$ & Date & Parameter & Std. & Error & t Value & $\overline{\mathrm{P}(>|t|)}$ \\
\hline $06 / 01 / 2006$ & 0.460 & & 0.062 & 7.455 & 0.000 & $07 / 07 / 2006$ & 0.481 & & 0.105 & 4.564 & 0.000 \\
\hline $13 / 01 / 2006$ & 0.461 & & 0.063 & 7.302 & 0.000 & $14 / 07 / 2006$ & 0.485 & & 0.106 & 4.588 & 0.000 \\
\hline $20 / 01 / 2006$ & 0.466 & & 0.066 & 7.107 & 0.000 & $21 / 07 / 2006$ & 0.490 & & 0.105 & 4.646 & 0.000 \\
\hline $27 / 01 / 2006$ & 0.466 & & 0.065 & 7.209 & 0.000 & $31 / 07 / 2006$ & 0.493 & & 0.105 & 4.687 & 0.000 \\
\hline 03/02/2006 & 0.465 & & 0.064 & 7.230 & 0.000 & $04 / 08 / 2006$ & 0.495 & & 0.107 & 4.644 & 0.000 \\
\hline $10 / 02 / 2006$ & 0.460 & & 0.065 & 7.071 & 0.000 & $11 / 08 / 2006$ & 0.493 & & 0.109 & 4.532 & 0.000 \\
\hline $17 / 02 / 2006$ & 0.458 & & 0.066 & 6.955 & 0.000 & $18 / 08 / 2006$ & 0.494 & & 0.109 & 4.538 & 0.000 \\
\hline $28 / 02 / 2006$ & 0.453 & & 0.065 & 6.968 & 0.000 & $25 / 08 / 2006$ & 0.488 & & 0.109 & 4.463 & 0.000 \\
\hline $03 / 03 / 2006$ & 0.452 & & 0.065 & 6.954 & 0.000 & $31 / 08 / 2006$ & 0.488 & & 0.109 & 4.466 & 0.000 \\
\hline $10 / 03 / 2006$ & 0.448 & & 0.064 & 6.955 & 0.000 & 08/09/2006 & 0.387 & & 0.074 & 5.252 & 0.000 \\
\hline $17 / 03 / 2006$ & 0.447 & & 0.065 & 6.849 & 0.000 & $15 / 09 / 2006$ & 0.376 & & 0.074 & 5.107 & 0.000 \\
\hline $24 / 03 / 2006$ & 0.447 & & 0.065 & 6.833 & 0.000 & $22 / 09 / 2006$ & 0.368 & & 0.075 & 4.885 & 0.000 \\
\hline $31 / 03 / 2006$ & 0.445 & & 0.063 & 7.074 & 0.000 & $29 / 09 / 2006$ & 0.361 & & 0.076 & 4.723 & 0.000 \\
\hline $07 / 04 / 2006$ & 0.446 & & 0.064 & 6.981 & 0.000 & $06 / 10 / 2006$ & 0.357 & & 0.077 & 4.613 & 0.000 \\
\hline $13 / 04 / 2006$ & 0.447 & & 0.065 & 6.903 & 0.000 & $13 / 10 / 2006$ & 0.350 & & 0.077 & 4.521 & 0.000 \\
\hline $21 / 04 / 2006$ & 0.451 & & 0.065 & 6.953 & 0.000 & $20 / 10 / 2006$ & 0.347 & & 0.077 & 4.511 & 0.000 \\
\hline $28 / 04 / 2006$ & 0.446 & & 0.066 & 6.761 & 0.000 & $27 / 10 / 2006$ & 0.336 & & 0.077 & 4.384 & 0.000 \\
\hline $05 / 05 / 2006$ & 0.422 & & 0.086 & 4.878 & 0.000 & $31 / 10 / 2006$ & 0.326 & & 0.079 & 4.144 & 0.000 \\
\hline $12 / 05 / 2006$ & 0.424 & & 0.087 & 4.878 & 0.000 & $03 / 11 / 2006$ & 0.324 & & 0.079 & 4.118 & 0.000 \\
\hline $19 / 05 / 2006$ & 0.425 & & 0.087 & 4.891 & 0.000 & $10 / 11 / 2006$ & 0.329 & & 0.079 & 4.179 & 0.000 \\
\hline $26 / 05 / 2006$ & 0.431 & & 0.087 & 4.963 & 0.000 & $17 / 11 / 2006$ & 0.332 & & 0.079 & 4.211 & 0.000 \\
\hline $31 / 05 / 2006$ & 0.457 & & 0.099 & 4.625 & 0.000 & $22 / 11 / 2006$ & 0.336 & & 0.079 & 4.259 & 0.000 \\
\hline $02 / 06 / 2006$ & 0.463 & & 0.099 & 4.676 & 0.000 & $30 / 11 / 2006$ & 0.445 & & 0.073 & 6.112 & 0.000 \\
\hline 09/06/2006 & 0.475 & & 0.101 & 4.693 & 0.000 & $08 / 12 / 2006$ & 0.446 & & 0.072 & 6.156 & 0.000 \\
\hline $15 / 06 / 2006$ & 0.479 & & 0.101 & 4.721 & 0.000 & $15 / 12 / 2006$ & 0.447 & & 0.072 & 6.171 & 0.000 \\
\hline $23 / 06 / 2006$ & 0.480 & & 0.104 & 4.625 & 0.000 & $22 / 12 / 2006$ & 0.448 & & 0.072 & 6.197 & 0.000 \\
\hline $30 / 06 / 2006$ & 0.478 & & 0.105 & 4.535 & 0.000 & $29 / 12 / 2006$ & 0.445 & & 0.072 & 6.172 & 0.000 \\
\hline
\end{tabular}


Table 5: Characteristics of the $\ln (\gamma)$ parameter from the Lane Financial model on the sub period 1st January 2006 - 31st December 2006.

The following table summaries the main statistics relative to the $\ln (\gamma)$ parameter of the Lane Financial model:

$$
\ln \left(Y_{i t}\right)=\ln \left(\gamma_{i t}\right)+\alpha_{t} \ln \left(V_{i}\right)+\beta_{t} \ln \left(Z_{i}\right)+\epsilon_{i t} .
$$

The estimation was done between 1st January 2004 and 31st December 2006. The regression results of the last year are presented.

\begin{tabular}{|c|c|c|c|c|c|c|c|c|c|c|}
\hline Date & Parameter & Std. & Error & $\mathrm{t}$ Value & $\mathrm{P}(>|t|)$ & Date & Parameter & Std. Error & $\mathrm{t}$ Value & $\mathrm{P}(>|t|)$ \\
\hline $06 / 01 / 2006$ & -1.258 & & 0.271 & -4.647 & 0.000 & $07 / 07 / 2006$ & -0.911 & 0.468 & -1.946 & 0.061 \\
\hline $13 / 01 / 2006$ & -1.282 & & 0.277 & -4.621 & 0.000 & $14 / 07 / 2006$ & -0.876 & 0.469 & -1.867 & 0.072 \\
\hline $20 / 01 / 2006$ & -1.284 & & 0.288 & -4.457 & 0.000 & $21 / 07 / 2006$ & -0.844 & 0.468 & -1.805 & 0.082 \\
\hline $27 / 01 / 2006$ & -1.285 & & 0.284 & -4.522 & 0.000 & $31 / 07 / 2006$ & -0.799 & 0.467 & -1.711 & 0.098 \\
\hline $03 / 02 / 2006$ & -1.300 & & 0.283 & -4.598 & 0.000 & $04 / 08 / 2006$ & -0.788 & 0.473 & -1.665 & 0.107 \\
\hline $10 / 02 / 2006$ & -1.331 & & 0.286 & -4.657 & 0.000 & $11 / 08 / 2006$ & -0.796 & 0.483 & -1.649 & 0.110 \\
\hline $17 / 02 / 2006$ & -1.364 & & 0.289 & -4.715 & 0.000 & $18 / 08 / 2006$ & -0.787 & 0.484 & -1.627 & 0.115 \\
\hline $28 / 02 / 2006$ & -1.384 & & 0.285 & -4.851 & 0.000 & $25 / 08 / 2006$ & -0.820 & 0.486 & -1.690 & 0.102 \\
\hline $03 / 03 / 2006$ & -1.389 & & 0.286 & -4.865 & 0.000 & $31 / 08 / 2006$ & -0.819 & 0.485 & -1.688 & 0.102 \\
\hline $10 / 03 / 2006$ & -1.401 & & 0.283 & -4.946 & 0.000 & 08/09/2006 & -1.286 & 0.298 & -4.321 & 0.000 \\
\hline $17 / 03 / 2006$ & -1.413 & & 0.287 & -4.932 & 0.000 & $15 / 09 / 2006$ & -1.350 & 0.298 & -4.535 & 0.000 \\
\hline $24 / 03 / 2006$ & -1.413 & & 0.287 & -4.920 & 0.000 & $22 / 09 / 2006$ & -1.403 & 0.305 & -4.605 & 0.000 \\
\hline $31 / 03 / 2006$ & -1.378 & & 0.276 & -4.987 & 0.000 & $29 / 09 / 2006$ & -1.459 & 0.309 & -4.728 & 0.000 \\
\hline $07 / 04 / 2006$ & -1.369 & & 0.280 & -4.882 & 0.000 & $06 / 10 / 2006$ & -1.483 & 0.313 & -4.743 & 0.000 \\
\hline $13 / 04 / 2006$ & -1.353 & & 0.284 & -4.757 & 0.000 & $13 / 10 / 2006$ & -1.528 & 0.313 & -4.880 & 0.000 \\
\hline $21 / 04 / 2006$ & -1.311 & & 0.285 & -4.594 & 0.000 & $20 / 10 / 2006$ & -1.554 & 0.310 & -5.005 & 0.000 \\
\hline $28 / 04 / 2006$ & -1.335 & & 0.290 & -4.605 & 0.000 & $27 / 10 / 2006$ & -1.573 & 0.310 & -5.073 & 0.000 \\
\hline $05 / 05 / 2006$ & -1.229 & & 0.384 & -3.204 & 0.003 & $31 / 10 / 2006$ & -1.611 & 0.318 & -5.075 & 0.000 \\
\hline $12 / 05 / 2006$ & -1.207 & & 0.385 & -3.133 & 0.004 & $03 / 11 / 2006$ & -1.619 & 0.318 & -5.089 & 0.000 \\
\hline $19 / 05 / 2006$ & -1.184 & & 0.386 & -3.069 & 0.005 & $10 / 11 / 2006$ & -1.586 & 0.318 & -4.981 & 0.000 \\
\hline $26 / 05 / 2006$ & -1.151 & & 0.385 & -2.989 & 0.006 & $17 / 11 / 2006$ & -1.573 & 0.319 & -4.931 & 0.000 \\
\hline $31 / 05 / 2006$ & -1.080 & & 0.438 & -2.465 & 0.020 & $22 / 11 / 2006$ & -1.548 & 0.319 & -4.850 & 0.000 \\
\hline 02/06/2006 & -1.047 & & 0.439 & -2.384 & 0.024 & $30 / 11 / 2006$ & -1.172 & 0.309 & -3.795 & 0.000 \\
\hline 09/06/2006 & -0.980 & & 0.450 & -2.179 & 0.038 & $08 / 12 / 2006$ & -1.162 & 0.307 & -3.778 & 0.000 \\
\hline $15 / 06 / 2006$ & -0.957 & & 0.450 & -2.128 & 0.042 & $15 / 12 / 2006$ & -1.160 & 0.307 & -3.775 & 0.000 \\
\hline $23 / 06 / 2006$ & -0.935 & & 0.461 & -2.030 & 0.052 & $22 / 12 / 2006$ & -1.161 & 0.307 & -3.786 & 0.000 \\
\hline $30 / 06 / 2006$ & -0.941 & & 0.468 & -2.012 & 0.054 & $29 / 12 / 2006$ & -1.177 & 0.306 & -3.841 & 0.000 \\
\hline
\end{tabular}


Table 6: Characteristics of the $\beta$ parameter from the Lane Financial model on the sub period 1st January 2006 - 31st December 2006.

The following table summaries the main statistics relative to the $\beta$ parameter of the Lane Financial model:

$$
\ln \left(Y_{i t}\right)=\ln \left(\gamma_{i t}\right)+\alpha_{t} \ln \left(V_{i}\right)+\beta_{t} \ln \left(Z_{i}\right)+\epsilon_{i t} .
$$

The estimation was done between 1st January 2004 and 31st December 2006. The regression results of the last year are presented.

\begin{tabular}{|c|c|c|c|c|c|c|c|c|c|c|}
\hline Date & Parameter & Std. & Error & t Value & $\mathrm{P}(>|t|)$ & Date & Parameter & Std. Error & t Value & $\mathrm{P}(>|t|)$ \\
\hline $06 / 01 / 2006$ & -0.310 & & 0.401 & -0.773 & 0.444 & $07 / 07 / 2006$ & -0.706 & 0.548 & -1.289 & 0.208 \\
\hline $13 / 01 / 2006$ & -0.403 & & 0.411 & -0.980 & 0.334 & $14 / 07 / 2006$ & -0.698 & 0.549 & -1.271 & 0.214 \\
\hline $20 / 01 / 2006$ & -0.471 & & 0.427 & -1.103 & 0.277 & $21 / 07 / 2006$ & -0.709 & 0.547 & -1.295 & 0.205 \\
\hline $27 / 01 / 2006$ & -0.482 & & 0.421 & -1.144 & 0.260 & $31 / 07 / 2006$ & -0.674 & 0.546 & -1.234 & 0.227 \\
\hline $03 / 02 / 2006$ & -0.485 & & 0.419 & -1.159 & 0.254 & $04 / 08 / 2006$ & -0.694 & 0.553 & -1.255 & 0.220 \\
\hline $10 / 02 / 2006$ & -0.504 & & 0.424 & -1.191 & 0.241 & $11 / 08 / 2006$ & -0.698 & 0.565 & -1.235 & 0.227 \\
\hline $17 / 02 / 2006$ & -0.575 & & 0.429 & -1.342 & 0.188 & $18 / 08 / 2006$ & -0.692 & 0.566 & -1.223 & 0.231 \\
\hline $28 / 02 / 2006$ & -0.576 & & 0.423 & -1.363 & 0.181 & $25 / 08 / 2006$ & -0.751 & 0.568 & -1.322 & 0.197 \\
\hline $03 / 03 / 2006$ & -0.577 & & 0.423 & -1.364 & 0.181 & $31 / 08 / 2006$ & -0.750 & 0.568 & -1.321 & 0.197 \\
\hline $10 / 03 / 2006$ & -0.600 & & 0.420 & -1.430 & 0.161 & $08 / 09 / 2006$ & -0.462 & 0.363 & -1.273 & 0.208 \\
\hline $17 / 03 / 2006$ & -0.637 & & 0.424 & -1.501 & 0.142 & $15 / 09 / 2006$ & -0.472 & 0.363 & -1.299 & 0.199 \\
\hline $24 / 03 / 2006$ & -0.647 & & 0.426 & -1.520 & 0.137 & $22 / 09 / 2006$ & -0.524 & 0.372 & -1.409 & 0.164 \\
\hline $31 / 03 / 2006$ & -0.671 & & 0.409 & -1.638 & 0.110 & $29 / 09 / 2006$ & -0.570 & 0.376 & -1.516 & 0.135 \\
\hline $07 / 04 / 2006$ & -0.707 & & 0.415 & -1.702 & 0.097 & $06 / 10 / 2006$ & -0.608 & 0.381 & -1.595 & 0.116 \\
\hline $13 / 04 / 2006$ & -0.693 & & 0.421 & -1.645 & 0.108 & $13 / 10 / 2006$ & -0.621 & 0.382 & -1.625 & 0.110 \\
\hline $21 / 04 / 2006$ & -0.673 & & 0.423 & -1.593 & 0.120 & $20 / 10 / 2006$ & -0.618 & 0.379 & -1.631 & 0.109 \\
\hline $28 / 04 / 2006$ & -0.663 & & 0.429 & -1.544 & 0.131 & $27 / 10 / 2006$ & -0.577 & 0.378 & -1.525 & 0.133 \\
\hline $05 / 05 / 2006$ & -0.408 & & 0.449 & -0.909 & 0.371 & $31 / 10 / 2006$ & -0.488 & 0.387 & -1.259 & 0.213 \\
\hline $12 / 05 / 2006$ & -0.406 & & 0.451 & -0.901 & 0.375 & $03 / 11 / 2006$ & -0.483 & 0.388 & -1.246 & 0.218 \\
\hline $19 / 05 / 2006$ & -0.388 & & 0.451 & -0.860 & 0.397 & $10 / 11 / 2006$ & -0.472 & 0.388 & -1.215 & 0.229 \\
\hline $26 / 05 / 2006$ & -0.395 & & 0.450 & -0.877 & 0.388 & $17 / 11 / 2006$ & -0.467 & 0.389 & -1.201 & 0.235 \\
\hline $31 / 05 / 2006$ & -0.638 & & 0.512 & -1.245 & 0.223 & $22 / 11 / 2006$ & -0.457 & 0.389 & -1.172 & 0.246 \\
\hline $02 / 06 / 2006$ & -0.637 & & 0.513 & -1.241 & 0.225 & $30 / 11 / 2006$ & -0.605 & 0.390 & -1.551 & 0.126 \\
\hline $09 / 06 / 2006$ & -0.710 & & 0.526 & -1.351 & 0.187 & $08 / 12 / 2006$ & -0.586 & 0.389 & -1.507 & 0.137 \\
\hline $15 / 06 / 2006$ & -0.709 & & 0.526 & -1.347 & 0.188 & $15 / 12 / 2006$ & -0.580 & 0.389 & -1.491 & 0.141 \\
\hline $23 / 06 / 2006$ & -0.665 & & 0.539 & -1.234 & 0.227 & $22 / 12 / 2006$ & -0.596 & 0.388 & -1.538 & 0.129 \\
\hline $30 / 06 / 2006$ & -0.717 & & 0.547 & -1.311 & 0.200 & $29 / 12 / 2006$ & -0.597 & 0.387 & -1.540 & 0.129 \\
\hline
\end{tabular}


Table 7: Autoregressive component of the Lane Financial model

This table summarizes the main characteristics of the autoregressive part of the Lane Financial model (equation (15)). If the column "Order" indicates the order of the autoregressive component of the model, the others are relative to the coefficient $\Phi_{i 1}^{2}$. Following the previous analysis, in order to take into account the new issues in the mode, the study is done for three sub periods: from 1st May 2005 to 1st September 2005, from 1st September 2005 to 1st January 2006 and from 1st January 2006 to 1st May 2006. In the table, a "-" indicates that the order of the autoregressive model is zero whereas empty value indicates that the issue is not traded for the considered sub period.

\begin{tabular}{|c|c|c|c|c|c|c|c|c|c|c|c|c|}
\hline \multirow[b]{2}{*}{ Bond } & \multicolumn{4}{|c|}{$2005-05-01$ 2005-09-01 } & \multicolumn{4}{|c|}{ 2005-09-01 2006-01-01 } & \multicolumn{4}{|c|}{ 2006-01-01 2006-05-01 } \\
\hline & Param & Std. Error & t Value & Order & Param & Std. Error & t Value & Order & Param & Std. Error & $\mathrm{t}$ Value & Order \\
\hline 2 & 0.618 & 0.020 & 31.592 & 1 & - & - & - & - & 0.870 & 0.024 & 36.580 & 1 \\
\hline 4 & 0.334 & 0.024 & 14.008 & 1 & - & - & - & - & 0.601 & 0.013 & 47.656 & 1 \\
\hline 5 & 0.785 & 0.035 & 22.413 & 1 & - & - & - & - & & & & \\
\hline 6 & & & & & - & - & - & - & 0.968 & 0.013 & 74.585 & 2 \\
\hline 9 & - & - & - & - & - & - & - & - & 0.573 & 0.011 & 52.707 & 1 \\
\hline 10 & - & - & - & - & - & - & - & - & 0.847 & 0.012 & 67.756 & 2 \\
\hline 11 & & & & & & & & & 0.494 & 0.013 & 36.992 & 2 \\
\hline 12 & 0.495 & 0.049 & 10.036 & 1 & 0.660 & 1.000 & 0.660 & 1 & 0.432 & 0.030 & 14.191 & 1 \\
\hline 13 & & & & & 0.877 & 1.414 & 0.620 & 2 & 0.463 & 0.041 & 11.201 & 1 \\
\hline 14 & & & & & 0.724 & 1.000 & 0.724 & 1 & 1.070 & 0.029 & 37.057 & 2 \\
\hline 19 & 0.819 & 0.065 & 12.529 & 1 & 0.388 & 1.000 & 0.388 & 1 & & & & \\
\hline 20 & - & - & - & - & 0.423 & 1.000 & 0.423 & 1 & 0.631 & 0.026 & 24.389 & 1 \\
\hline 21 & 0.868 & 0.026 & 33.852 & 1 & - & - & - & - & - & - & - & - \\
\hline 22 & 0.688 & 0.027 & 25.883 & 1 & & & & & & & & \\
\hline 23 & - & - & - & - & & & & & & & & \\
\hline 24 & 0.640 & 0.028 & 22.626 & 1 & 0.816 & 1.000 & 0.816 & 1 & 0.787 & 0.035 & 22.719 & 1 \\
\hline 25 & 0.691 & 0.184 & 3.759 & 1 & & & & & & & & \\
\hline 26 & - & - & - & - & 0.737 & 1.000 & 0.737 & 1 & 1.208 & 0.012 & 97.108 & 4 \\
\hline 27 & 0.783 & 0.014 & 55.272 & 1 & 0.718 & 1.000 & 0.718 & 1 & 0.637 & 0.022 & 28.634 & 1 \\
\hline 28 & 0.803 & 0.013 & 63.852 & 1 & 0.727 & 1.000 & 0.727 & 1 & 0.621 & 0.022 & 28.782 & 1 \\
\hline 29 & 0.780 & 0.022 & 35.417 & 1 & 0.419 & 1.000 & 0.419 & 1 & 0.790 & 0.039 & 20.292 & 1 \\
\hline 30 & - & - & - & - & 0.687 & 1.000 & 0.687 & 1 & 0.799 & 0.110 & 7.277 & 1 \\
\hline 39 & 0.571 & 0.024 & 23.986 & 1 & & & & & & & & \\
\hline 40 & 0.822 & 0.011 & 73.766 & 1 & & & & & & & & \\
\hline 41 & 0.654 & 0.026 & 25.287 & 1 & 0.820 & 1.000 & 0.820 & 1 & 0.837 & 0.012 & 67.555 & 1 \\
\hline 42 & 0.632 & 0.024 & 26.341 & 1 & 0.820 & 1.000 & 0.820 & 1 & 0.793 & 0.040 & 19.955 & 1 \\
\hline 43 & 0.634 & 0.025 & 25.011 & 1 & 0.963 & 1.414 & 0.681 & 2 & 0.661 & 0.012 & 54.944 & 1 \\
\hline 44 & - & - & - & - & 0.898 & 1.414 & 0.635 & 2 & 0.742 & 0.013 & 57.812 & 1 \\
\hline 45 & & & & & 0.851 & 1.732 & 0.491 & 3 & 0.682 & 0.015 & 45.396 & 1 \\
\hline 46 & & & & & 0.662 & 1.000 & 0.662 & 1 & 0.781 & 0.012 & 63.471 & 1 \\
\hline 47 & 0.464 & 0.038 & 12.223 & 1 & 0.702 & 1.000 & 0.702 & 1 & 0.604 & 0.047 & 12.959 & 1 \\
\hline
\end{tabular}


Table 8: Estimation of the $\lambda$ parameter of the Fermat temporal model. This table presents some statistics on the $\lambda$ parameter of the Fermat temporal model:

$$
Y_{i t}=X_{i}+\lambda \times \frac{1}{m_{i}} \times \sqrt{X_{i}\left(1-X_{i}\right)}+n u_{i t} .
$$

The estimation was done between 1st January 2004 and 31st December 2006 but only the regression results of the last year are presented.

\begin{tabular}{|c|c|c|c|c|c|c|c|c|c|c|}
\hline Date & Parameter & Std. & Error & $\mathrm{t}$ Value & $\mathrm{P}(>|t|)$ & Date & Parameter & Std. Error & $\mathrm{t}$ Value & $\mathrm{P}(>|t|)$ \\
\hline $06 / 01 / 2006$ & 0.482 & & 0.045 & 10.626 & 0.000 & $07 / 07 / 2006$ & 0.780 & 0.240 & 3.253 & 0.003 \\
\hline $13 / 01 / 2006$ & 0.482 & & 0.050 & 9.688 & 0.000 & $14 / 07 / 2006$ & 0.797 & 0.240 & 3.326 & 0.002 \\
\hline $20 / 01 / 2006$ & 0.485 & & 0.058 & 8.345 & 0.000 & $21 / 07 / 2006$ & 0.814 & 0.245 & 3.330 & 0.002 \\
\hline $27 / 01 / 2006$ & 0.485 & & 0.060 & 8.137 & 0.000 & $31 / 07 / 2006$ & 0.835 & 0.245 & 3.412 & 0.002 \\
\hline $03 / 02 / 2006$ & 0.482 & & 0.056 & 8.546 & 0.000 & $04 / 08 / 2006$ & 0.850 & 0.258 & 3.295 & 0.003 \\
\hline $10 / 02 / 2006$ & 0.476 & & 0.058 & 8.224 & 0.000 & $11 / 08 / 2006$ & 0.859 & 0.261 & 3.295 & 0.003 \\
\hline $17 / 02 / 2006$ & 0.474 & & 0.059 & 8.097 & 0.000 & $18 / 08 / 2006$ & 0.867 & 0.261 & 3.323 & 0.002 \\
\hline $28 / 02 / 2006$ & 0.471 & & 0.057 & 8.253 & 0.000 & $25 / 08 / 2006$ & 0.868 & 0.261 & 3.329 & 0.002 \\
\hline $03 / 03 / 2006$ & 0.470 & & 0.057 & 8.226 & 0.000 & $31 / 08 / 2006$ & 0.868 & 0.261 & 3.329 & 0.002 \\
\hline $10 / 03 / 2006$ & 0.472 & & 0.057 & 8.289 & 0.000 & 08/09/2006 & 0.657 & 0.131 & 5.003 & 0.000 \\
\hline $17 / 03 / 2006$ & 0.475 & & 0.063 & 7.589 & 0.000 & $15 / 09 / 2006$ & 0.635 & 0.131 & 4.828 & 0.000 \\
\hline $24 / 03 / 2006$ & 0.476 & & 0.063 & 7.571 & 0.000 & $22 / 09 / 2006$ & 0.630 & 0.149 & 4.215 & 0.000 \\
\hline $31 / 03 / 2006$ & 0.491 & & 0.069 & 7.162 & 0.000 & $29 / 09 / 2006$ & 0.617 & 0.151 & 4.093 & 0.000 \\
\hline $07 / 04 / 2006$ & 0.501 & & 0.080 & 6.269 & 0.000 & $06 / 10 / 2006$ & 0.614 & 0.153 & 4.011 & 0.000 \\
\hline $13 / 04 / 2006$ & 0.507 & & 0.083 & 6.121 & 0.000 & $13 / 10 / 2006$ & 0.601 & 0.153 & 3.915 & 0.000 \\
\hline $21 / 04 / 2006$ & 0.523 & & 0.083 & 6.343 & 0.000 & $20 / 10 / 2006$ & 0.590 & 0.146 & 4.055 & 0.000 \\
\hline $28 / 04 / 2006$ & 0.521 & & 0.083 & 6.278 & 0.000 & $27 / 10 / 2006$ & 0.590 & 0.141 & 4.176 & 0.000 \\
\hline $05 / 05 / 2006$ & 0.596 & & 0.111 & 5.378 & 0.000 & $31 / 10 / 2006$ & 0.582 & 0.142 & 4.107 & 0.000 \\
\hline $12 / 05 / 2006$ & 0.609 & & 0.113 & 5.403 & 0.000 & $03 / 11 / 2006$ & 0.580 & 0.142 & 4.100 & 0.000 \\
\hline $19 / 05 / 2006$ & 0.617 & & 0.113 & 5.482 & 0.000 & $10 / 11 / 2006$ & 0.587 & 0.141 & 4.149 & 0.000 \\
\hline $26 / 05 / 2006$ & 0.630 & & 0.115 & 5.487 & 0.000 & $17 / 11 / 2006$ & 0.589 & 0.141 & 4.163 & 0.000 \\
\hline $31 / 05 / 2006$ & 0.698 & & 0.242 & 2.882 & 0.007 & $22 / 11 / 2006$ & 0.594 & 0.141 & 4.197 & 0.000 \\
\hline $02 / 06 / 2006$ & 0.707 & & 0.243 & 2.908 & 0.007 & $30 / 11 / 2006$ & 0.596 & 0.141 & 4.242 & 0.000 \\
\hline $09 / 06 / 2006$ & 0.735 & & 0.244 & 3.007 & 0.005 & $08 / 12 / 2006$ & 0.597 & 0.138 & 4.338 & 0.000 \\
\hline $15 / 06 / 2006$ & 0.744 & & 0.244 & 3.044 & 0.005 & $15 / 12 / 2006$ & 0.595 & 0.136 & 4.372 & 0.000 \\
\hline $23 / 06 / 2006$ & 0.750 & & 0.231 & 3.239 & 0.003 & $22 / 12 / 2006$ & 0.596 & 0.137 & 4.352 & 0.000 \\
\hline $30 / 06 / 2006$ & 0.766 & & 0.235 & 3.264 & 0.003 & $29 / 12 / 2006$ & 0.592 & 0.137 & 4.331 & 0.000 \\
\hline
\end{tabular}


Table 9: Autoregressive component of the Fermat Capital Management model

This table summaries the main characteristics of the autoregressive part of the Lane Financial model (see equation (16)). If the column "Order" indicates the order of the autoregressive component of the model, the others are relative to the coefficient $\Phi_{i 3}^{2}$. Following the previous analysis, in order to take into account the new issues in the mode, the study is done for three sub periods: from 1st May 2005 to 1st September 2005, from 1st September 2005 to 1st January 2006 and from 1st January 2006 to 1st May 2006. In the table, a "-" indicates that the order of the autoregressive model is zero whereas empty value indicates that the issue is not traded for the considered sub period.

\begin{tabular}{|c|c|c|c|c|c|c|c|c|c|c|c|c|}
\hline \multirow[b]{2}{*}{ Bond } & \multicolumn{4}{|c|}{ 2005-05-01 2005-09-01 } & \multicolumn{4}{|c|}{ 2005-09-01 2006-01-01 } & \multicolumn{4}{|c|}{ 2006-01-01 2006-05-01 } \\
\hline & Param & Std. Error & t Value & Order & Param & Std. Error & t Value & Order & Param & Std. Error & t Value & Order \\
\hline 1 & & & & & & & & & 0.625 & 0.001 & 1106.064 & 1 \\
\hline 2 & - & - & - & - & 0.707 & 0.004 & 172.680 & 1 & 0.861 & 0.003 & 335.833 & 1 \\
\hline 3 & 0.786 & 0.001 & 1249.652 & 1 & 0.362 & 0.002 & 148.850 & 1 & 0.858 & 0.003 & 319.988 & 1 \\
\hline 4 & 0.358 & 0.001 & 300.334 & 1 & - & - & - & - & 0.799 & 0.001 & 751.207 & 1 \\
\hline 5 & 0.693 & 0.004 & 186.202 & 1 & - & - & - & - & & & & \\
\hline 6 & 0.500 & 0.001 & 634.716 & 1 & - & - & - & - & 0.962 & 0.001 & 769.577 & 3 \\
\hline 7 & & & & & - & - & - & - & 0.851 & 0.003 & 302.639 & 1 \\
\hline 8 & - & - & - & - & - & - & - & - & 0.796 & 0.001 & 810.639 & 1 \\
\hline 9 & 0.389 & 0.002 & 233.013 & 1 & - & - & - & - & 1.208 & 0.001 & 1588.800 & 2 \\
\hline 10 & 0.405 & 0.003 & 160.979 & 1 & - & - & - & - & 1.207 & 0.001 & 1214.218 & 2 \\
\hline 11 & & & & & & & & 1 & 0.788 & 0.001 & 802.605 & 2 \\
\hline 12 & - & - & - & - & 0.754 & 0.000 & 4668.099 & 1 & 0.773 & 0.000 & 1714.113 & 1 \\
\hline 13 & & & & & 0.693 & 0.005 & 138.225 & 1 & 0.775 & 0.005 & 161.738 & 1 \\
\hline 14 & & & & & 0.762 & 0.010 & 75.751 & 1 & 0.822 & 0.005 & 156.611 & 1 \\
\hline 15 & & & & & 0.756 & 0.032 & 23.660 & 1 & 0.753 & 0.043 & 17.536 & 1 \\
\hline 16 & & & & & 0.786 & 0.000 & 1622.802 & 1 & 0.783 & 0.001 & 1379.544 & 1 \\
\hline 17 & & & & & & & & & 1.063 & 0.001 & 744.193 & 2 \\
\hline 18 & & & & & & & & & 1.124 & 0.001 & 801.674 & 2 \\
\hline 19 & 0.652 & 0.001 & 501.357 & 1 & 0.754 & 0.000 & 1508.348 & 1 & & & & \\
\hline 20 & - & - & - & - & 0.410 & 0.001 & 311.460 & - & 0.717 & 0.001 & 723.343 & 1 \\
\hline 21 & - & - & - & - & - & - & - & 1 & 0.534 & 0.000 & 1334.338 & 1 \\
\hline 22 & - & - & - & - & & & & & & & & \\
\hline 23 & - & - & - & - & & & & & & & & \\
\hline 24 & - & - & - & - & 0.829 & 0.005 & 157.483 & 1 & 0.710 & 0.001 & 531.329 & 1 \\
\hline 25 & 0.335 & 0.002 & 221.036 & 2 & & & & & & & & \\
\hline 26 & - & - & - & - & 0.414 & 0.002 & 237.015 & 1 & 1.202 & 0.001 & 2183.210 & 2 \\
\hline 27 & 0.413 & 0.000 & 837.989 & 1 & 0.773 & 0.000 & 1636.829 & 1 & 0.869 & 0.000 & 4203.317 & 1 \\
\hline 28 & 0.427 & 0.001 & 603.630 & 1 & 0.777 & 0.001 & 1390.094 & 1 & 0.849 & 0.000 & 4109.931 & 1 \\
\hline 29 & 0.670 & 0.001 & 476.746 & 1 & 0.746 & 0.002 & 336.468 & 1 & 0.757 & 0.003 & 217.310 & 1 \\
\hline 30 & 0.618 & 0.001 & 483.318 & 1 & 0.753 & 0.011 & 66.297 & 1 & 0.742 & 0.001 & 655.419 & 1 \\
\hline 31 & 0.617 & 0.001 & 503.717 & 1 & 0.753 & 0.011 & 66.297 & 1 & 0.742 & 0.001 & 655.445 & 1 \\
\hline 32 & 0.767 & 0.001 & 543.539 & 1 & 0.834 & 0.007 & 124.131 & 1 & 0.742 & 0.004 & 202.769 & 1 \\
\hline 33 & 0.721 & 0.001 & 555.499 & 1 & 0.834 & 0.007 & 123.818 & 1 & 0.742 & 0.004 & 202.769 & 1 \\
\hline 34 & 0.375 & 0.002 & 189.565 & 1 & 0.809 & 0.003 & 270.318 & 1 & 0.744 & 0.002 & 396.156 & 1 \\
\hline 35 & - & - & - & - & 0.685 & 0.000 & 2252.385 & 1 & 0.645 & 0.000 & 1939.938 & 1 \\
\hline 36 & 0.330 & 0.001 & 294.972 & 1 & 0.764 & 0.001 & 710.136 & 1 & 0.599 & 0.000 & 1810.847 & 1 \\
\hline 37 & 0.537 & 0.000 & 2978.580 & 1 & - & - & - & - & 0.858 & 0.000 & 3164.153 & 1 \\
\hline 38 & 0.511 & 0.001 & 572.680 & 1 & 0.759 & 0.003 & 221.140 & 1 & 0.740 & 0.000 & 2593.326 & 1 \\
\hline 39 & 0.436 & 0.001 & 307.709 & 1 & & & & & & & & \\
\hline 40 & 0.307 & 0.001 & 345.197 & 2 & & & & & & & & \\
\hline 41 & 0.297 & 0.002 & 188.597 & 2 & 0.791 & 0.006 & 128.570 & 1 & 0.824 & 0.001 & 639.464 & 1 \\
\hline 42 & 0.283 & 0.001 & 190.905 & 2 & 0.794 & 0.006 & 124.474 & 1 & 0.805 & 0.003 & 241.005 & 1 \\
\hline 43 & 0.568 & 0.001 & 467.406 & 1 & 0.752 & 0.004 & 177.455 & 3 & 0.865 & 0.001 & 789.581 & 1 \\
\hline 44 & 0.739 & 0.002 & 461.679 & 1 & 0.456 & 0.009 & 50.037 & 2 & 1.377 & 0.001 & 1056.501 & 2 \\
\hline 45 & & & & & 0.771 & 0.004 & 183.764 & 3 & 0.799 & 0.001 & 647.687 & 1 \\
\hline 46 & & & & & - & - & - & - & 0.824 & 0.002 & 457.237 & 1 \\
\hline 47 & 0.440 & 0.000 & 1442.527 & 1 & 0.972 & 0.001 & 1693.014 & 2 & 0.816 & 0.001 & 1476.694 & 1 \\
\hline
\end{tabular}


Figure 6: Evolution of the parameters of the Lane Financial and Fermat Capital Management models for different types of risk.

This figures shows the evolution of the parameters of the Lane Financial and Fermat Capital Management models for different types of risk. The estimation is similar at the one done for the market as a whole. The total period is cut into several sub periods of four months in order to take into account the different new issues which appear regularly. The left axis stands for the parameters of the Lane Financial model whereas the right axis stands for the parameter $\lambda$ from the Fermat Capital Management model.

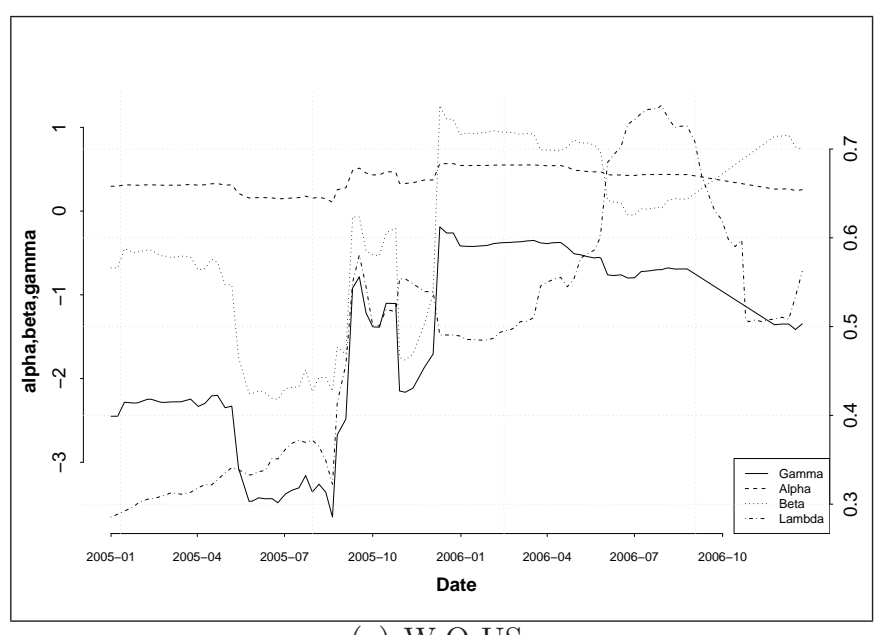

(a) W,Q-US

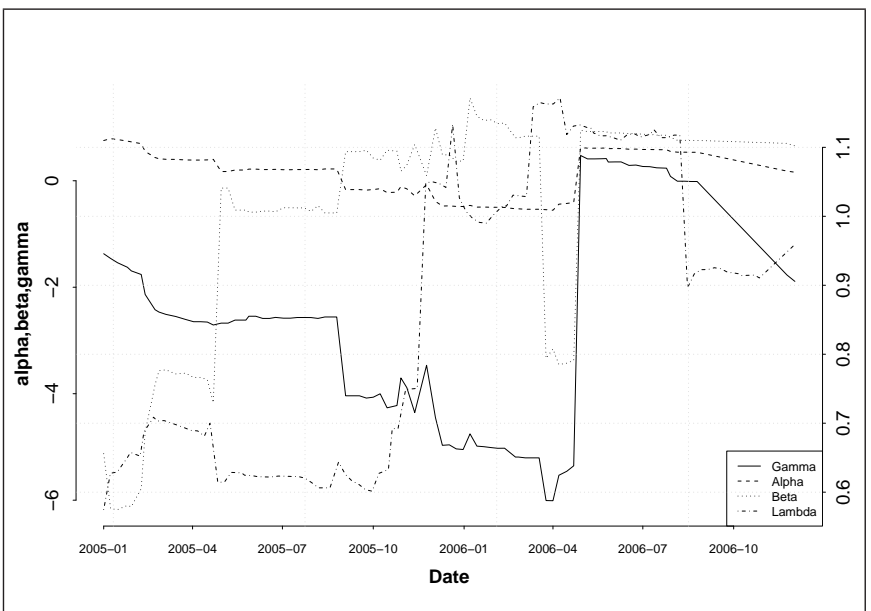

(c) Q-CA

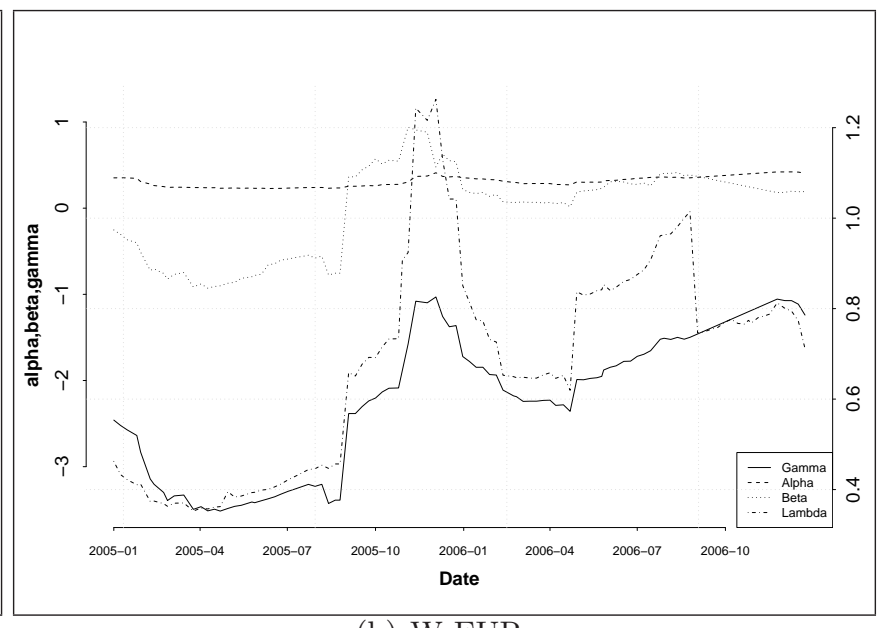

(b) W-EUR

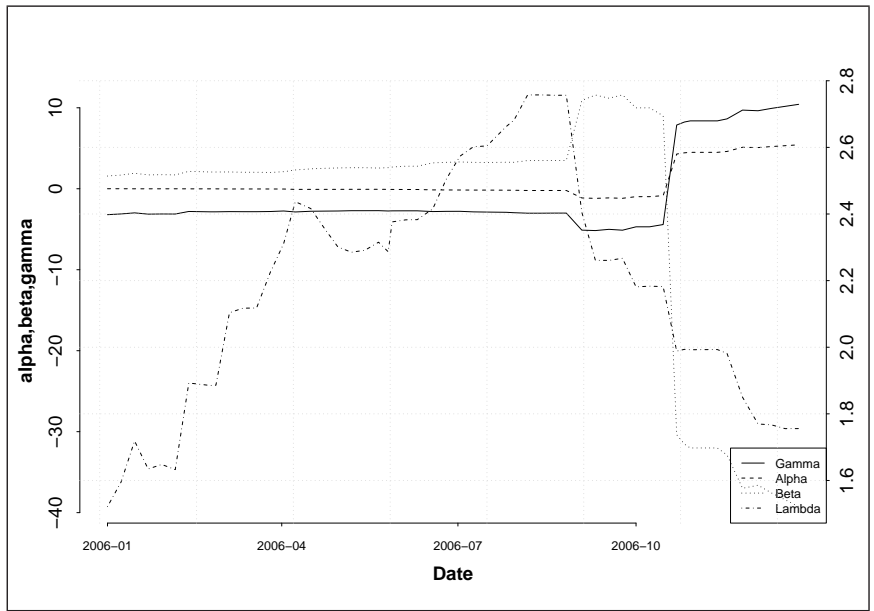

(d) Mortality 